\title{
On welfare reducing technological change in a
}

\author{
North-South framework*
}

H. Benchekroun ${ }^{a}$ and S. Vishwasrar

\begin{abstract}
Northern firms with patented technology can axport goods ow Wuthern markets and incur tariff costs or choose FDI and si the tariff. Wo examine the welfare effects of intellectual property protecti na his sctorio. When it is benefitial to do so, South offers a patent proti no indu ${ }^{2}$ DI. We show that a technological improvement in the Nor in an educe "' 'th's welfare. After a technological improvement, the Sout strll pro rs that hes fort however a longer patent protection may be requ $\circ \mathrm{d}$ induce $\mathrm{D}$ DI which can result in an overall decrease of South's we $e^{r}$ se. We also shov t'tat a more effective technology does not necessarily rear a ger patent prutection to induce FDI. JEL Classification: O14, O33, O. F13, 23. Keywords: Technology Improvements, Trade Policy, Foreign D ect ives, nent, Intellectual Property Rights, Technology Transfers.
\end{abstract}

*Acknowledgements: We would like to thank Sonia Laszlo, Shih-Tse Lo, Ngo Van Long and Dhanoos Sutthiphisal for very helpful comments. The first author acknowledges the financial support of the Social Sciences and Humanities Research Council of Canada. Please address all correspondence to Hassan Benchekroun, Department of Economics, McGill University, Montreal, QC, Canada H3A-2T7. Tel: 514398-2776. Fax: 514-398-4938. E-mail: hassan.benchekroun@mcgill.ca.

(a) Department of Economics and CIREQ, McGill University

(b) Department of Economics, Florida Atlantic University. 


\section{Introduction}

One of the primary benefits of foreign direct investment (FDI) for developing countries is its association with technology transfer. For the host country, the benefits of technology transfer are not limited to access to new goods or lower prices for consumers but also extend to domestic firms through the dissemination of cost reducing technolooie through learning and imitation. In an attempt to capture these benefits, de folopig vountries have sought to tailor policies to attract FDI and increase techno oy nstu. This paper investigates the welfare effects of technology improvements when $x$ uthern countries use intellectual property protection and tariffs to influence $t^{+}$ology transfer and FDI.

In our paper, Northern firms with patented technology c or cxport goods to Southern markets and incur tariff costs or choose FDI and avoia the tariff. Te examine the welfare effects of intellectual property protection $w^{2} \mathrm{de} \mathrm{t}^{\mathrm{T}} \mathrm{AS}$ scenario. When it is beneficial to do so, South offers a patent protection to duo MI. which impacts the marginal costs of prod nct or and tro affects the choice of the quantities to be produced. We show that a d ective chnology does not necessarily require a longer patent protection o indu FDI. find that technology improvements can influence the choice of FDI nd $P$ Rs in mays which may be immiserizing for Southern countries: a techn ogi d improvem in in the North can reduce South's welfare. After a technological at vent, the South still prefers that North does FDI, however a longer patent pr $\mathrm{pr}^{+} \mathrm{n}, \mathrm{y}$ be required to induce FDI which can result in an overall decrease of Sout clfare.

Our pap,r is related to a body of literature on FDI and technology transfer which looks at policies other than intellectual property rights. Matoo et al (2004) consider a Northern firm's choice between FDI and acquisition of domestic firms and find that when technology transfer is costly, the interaction between scale and competition effects provides incentives for Southern governments to limit the degree of foreign ownership. In a similar vein Brander and Spencer, 1987, Haufler and Wooton, 1999 and Fumagalli, 2003 study the welfare effects of tax and tariff policies on FDI and host country welfare. Our 
research is also linked to the literature on trade related intellectual property which examines Southern countries' incentives to protect patents based on R\&D and technology transfer considerations. Southern countries may have an incentive to protect Northern patents if the resulting research expenditures are very productive or result in innovations that benefit Southern countries (See Chin and Grossman, 1990, Diwan and Ru 'rick, 1991 and Deardorff, 1993). There is also an existing literature which studies the $r$ ve mpact of IPRs on technology transfer. (Taylor, 1993, Vishwasrao, 1994, and Z 5 B 3). On the other hand, Glass and Saggi (2002a, 2002b), in a model with e geno innovation and imitation show that tighter IPRs in the South can crowd out FDI a reduce innovation because of resources wasting ${ }^{1}$. Arguments that IPRs af ct he FDI decision enjoy theoretical as well as empirical support. Ferrantino (195 finds at mpltinationals firms will prefer to locate production where IPRs are well o gnid. In didition, Ferrantino also finds a tendency for U.S. firms to have highe that do not protect IPRs possibly in an tt , pt to cc ateal production technology. Lee and Mansfield (1996) using survey d a con U.S. At fonationals show that differences in intellectual property regimes sove slymicant in pact on the volume and composition of FDI. Lower levels of intell tual coperty pretection tend to reduce the volume of FDI and also the funds ir ested in row f f r lities in the host countries.

We construct a i. ael which can ures some of these features. In our model, a Northern firm chooses theth to service a Southern market through exports or FDI. FDI has the benefici en ct voiding the Southern tariff on imported goods but exposes the firm to the risk o mitation by Southern rivals. We assume that locating in a Southern country is necessary for imitation. We can think of this as a situation where imitation is costly and where FDI in the South lowers the costs of imitation perhaps because the technology has already been adapted for use in the South ${ }^{2}$. The Southern government can prevent

\footnotetext{
${ }^{1}$ In contrast with most other papers, in the Glass and Saggi model, better IPR protection in the South does not offer any special benefits to multinationals as opposed to importers thus tighter IPR protection tends to shift production to the North and reduces resources available for innovation.

${ }^{2}$ This is formalized in Glass and Saggi (2002), although the aspect of intellectual property protection
} 
imitation through patent protection. We use the length of patent protection as a measure of the level of IPR protection. Thus the Southern government picks the length of time before Southern firms are free to imitate the technology. The model is presented in Section 2. In Section 3 we introduce the technology improvement and determine its impact on the minimum FDI inducing patent length and on the South's welfare.

\section{The Model}

Consider a good that is only consumed in the South and produced one Northern firm that supplies the Southern market. There are no other s pp ers of the commodity in the South. The Northern firm can supply the Southern arket $b$ producing in the North and exporting to the South or by creating a subsidia in ty South FI). If the Northern firm exports it has to pay a per unit tariff at $I^{e}$ dencte the present value of the stream of profits earned by the Northern $n$ e southe Market if it chooses to export, we have:

where $\pi_{0}^{\tau}$ denotes the optin zed $f$ w rate of profits of the Northern firm in the Southern market when it sup ${ }^{r}$ es the Southern r rket through exports and when the per unit tariff is $\tau$.

If the Nor ern $\mathrm{t}$ m chooses FDI and sets a subsidiary in the South, it can sell whatever quanti+ it isht without having to pay the tariff. Patent protection in the South, for the North firm that chooses FDI, lasts for a period of time L. Until patents expire, the Northern firm's subsidiary has a monopoly in the Southern market and at $L$, Southern firms are able to reproduce the Northern firm's technology and generate the maximum welfare possible and the Northern firm's profits are zero ${ }^{3}$. Production in the South is studied is the scope of patents rather than the length.

${ }^{3}$ The market in the South may be perfectly competitive after patents expire or may be imperfectly competitive. For the results to hold, we only require that there are some gains to domestic consumers after patents expire and that the Northern firm's profits are lower. 
necessary for imitation to occur and the good cannot be imitated while it is imported. This can be justified by a lower imitation costs when trying to imitate a technology that has already been adapted for use in the South, or through knowledge spillovers through labor mobility etc. The time horizon is infinite.

Let $\Pi^{F D I}$ denote the present value of the stream of profits earned by ta Northern firm in the Southern market if it chooses FDI. We have

$$
\Pi^{F D I}=\int_{0}^{L} \pi_{0}^{F D I} e^{-r t} d t
$$

where $r>0$ denotes the interest rate and where $\pi_{0}^{F D I}$ denotes the sptimized flow rate of profits of the Northern firm in the Southern marke du ng the period of time that the patent is protected when it chooses FDI and. A or $L$, I assyne that the Northern firm's profits are zero.

Given a tariff rate $\tau$ and a patent length of exporting if $\Pi^{F D I} \geq \Pi^{e}$ which gives

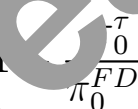

Note that in the absence o $\operatorname{tar}(\tau=\Omega)$ and patent protection $(L=0)$, the Northern firm may still choo FDI if the profit rom producing in the South $\pi_{0}^{F D I}$ are larger the the profits from $\times$ wo $\pi_{0}^{\tau=0}$. This lifference in profits and the decision to do FDI is then solely motiva d by more profitable environment to supply the Southern market from the So nd e, to example, to low wages in the South or high transportation costs.

In esta 'ishing condition (1) we implicitly assumed that the sunk-cost of setting-up the plant is zero. This assumption is made for simplicity: our results would not be qualitatively changed if we considered a positive sunk-cost. Note however that we do not assume that the fixed costs of operating the plant, or quasi-fixed costs are zero. Quasi fixed costs are costs that do not depend on the level of production but are incurred only when the firm produces a positive quantity of output: maintenance and operating expenses that are incurred regardless of the production level but can be avoided when 
production is zero ${ }^{4}$ (see for example Varian (2002)). For simplicity we focus on quasi-fixed costs and assume the sunk-cost is zero, and in the remainder of the paper the term fixed costs will refer to quasi fixed costs.

Let $W^{e}$ denote the present value of the stream of social welfare enjoyed in the South if the Northern firm chooses to export. We have:

$$
W^{e}=\int_{0}^{\infty} w_{0}^{\tau} e^{-r t} d t
$$

where $w_{0}^{\tau}$ denotes the flow rate of social welfare in the Sout ${ }^{1}$ hen $t_{1}$ Northern firm supplies the Southern market through exports and when the per unı tariff is $\tau$.

Let $W^{F D I}$ denote the present value of the stream of s ia welfare enjoyed in the South if the Northern firm chooses to do FDI. We have

$$
W^{F D I}=\int_{0}^{L} w_{0}^{F D I} e^{-\lambda} w_{0}^{s} e^{\infty}
$$

where $w_{0}^{F D I}$ denotes the optimized flow $r$ s soci. ${ }_{0}$ velfare of the South when the Northern chooses FDI during the r $r, c$ of time that the patent is protected and $w_{0}^{s}$ denotes the flow rate of soc rell e of the suth when the Northern firm chooses FDI after the expiration of the tent protection.

The South wou' prefer that the wrthern firm chooses FDI instead of exporting if $W^{F D I} \geq W^{e}$ wh: $^{\text {h }}$ y $1 \mathrm{ds}$

$$
e^{-r L} \geq \frac{w_{0}^{\tau}-w_{0}^{F D I}}{w_{0}^{s}-w_{0}^{F D I}}
$$

Con in $\mathrm{g}(1)$ and (3) gives that South prefers FDI and North chooses FDI $^{5}$ if $(L, \tau)$ are such thw

$$
\frac{w_{0}^{\tau}-w_{0}^{F D I}}{w_{0}^{s}-w_{0}^{F D I}} \leq e^{-r L} \leq 1-\frac{\pi_{0}^{\tau}}{\pi_{0}^{F D I}}
$$

\footnotetext{
${ }^{4}$ Other textbooks in microeconomics, managerial economics or industrial organization use different terminology such as operating or avoidable fixed costs to refer to quasi fixed costs (see for example Carlton and Perloff (2005)). For more details see Wang and Yang (2001).

${ }^{5}$ The South prefers exports and the North chooses exports when $1-\frac{\pi_{0}^{\tau}}{\pi_{0}^{F D I}}<e^{-r L}<\frac{w_{0}^{\tau}-w_{0}^{F D I}}{w_{0}^{s}-w_{0}^{F D I}}$.
} 
The condition 4 is intuitive: if the patent length is too long South no longer has an incentive to attract FDI and when the patent length is too short the Northern firm finds the FDI option unattractive.

We note that for the range of patent of length that makes FDI mutually attractive compared to the export option is non-empty iff

$$
\frac{w_{0}^{\tau}-w_{0}^{F D I}}{w_{0}^{s}-w_{0}^{F D I}} \leq 1-\frac{\pi_{0}^{\tau}}{\pi_{0}^{F D I}}
$$

that is

$$
\frac{w_{0}^{s}-w_{0}^{\tau}}{w_{0}^{s}-w_{0}^{F D I}} \geq \frac{\pi_{0}^{\tau}}{\pi_{0}^{F D I}}
$$

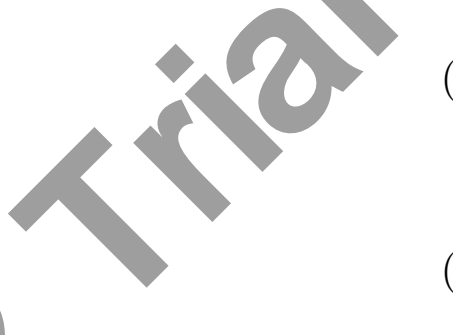

In the case of a linear demand and an affine cost function $r$ sow that for a significant set of parameters ${ }^{6}$ this inequality holds and therefore he interval ai patent lengths such that FDI is mutually beneficial to both parties $\mathrm{r}, \mathrm{t}$ empty.

\section{Technological impr}

A technological improvem th in pis paper represented by the reduction in the cost function it creates. can native been as a modification in the profits that depend on the qua $y$ produced Let $q$ denote the quantity produced, we consider technologica mpr en onts that result in an increase in the profits by $\beta q$ where $\beta \geq 0$. This tec a " gy $"$ provement can be viewed as a decrease in marginal cost.

The ural question of this paper is: Will the South always benefit from a technological improvement?

We consider the case where the South prefers FDI to export and can modify its patent length to always offer the minimum patent length, denoted $L_{\tau}(\beta)$, that induces the North-

\footnotetext{
${ }^{6} \mathrm{~A}$ set of parameters of positive measure where the parameters are the choke price, the slope of the demand function, the fixed cost and the marginal cost.

${ }^{7}$ We assume that the quality of the commodity is not affected by the change in technology.
} 
ern firm to choose FDI over exports ${ }^{8}$. To answer our main question we need to determine the impact of a technological improvement on the minimum FDI inducing patent length.

\subsection{The minimum FDI inducing patent length}

Given a tariff rate $\tau$ and a patent length $L$, the Northern firm will choose do FDI instead of exporting if

$$
\int_{0}^{L} \pi^{F D I} e^{-r t} d t \geq \int_{0}^{\infty} \pi^{\tau} e^{-r t} d t
$$

which after simplification yields

$$
L \geq L_{\tau}(\beta) \equiv \ln \left(\frac{\pi^{F D I}}{\pi^{F D I}-\pi^{\tau}}\right)^{\gamma}
$$

where $\pi^{\tau}$ and $\pi^{F D I}$ denote the profit of the northorn nirm when thare is a technological

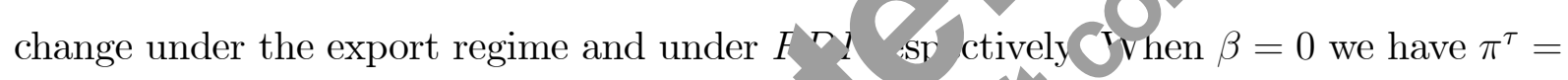
$\pi_{0}^{\tau}$ and $\pi^{F D I}=\pi_{0}^{F D I}$. The minimum FDJ II clis paten length prior to a technological improvement is $L_{\tau}(0)$.

Determining the impact of a $+\mathrm{h}^{1}$, ical in $\mathrm{in}_{\mathrm{s}}$ ovement for any $\beta$ positive is difficult. The quantities produced : each resime (exprt, FDI, post patent protection) will in general change due to he tec. gical rovement. Let $q^{F D I}$ denote the quantity chosen by the Northern fir. der FDI and denote the quantity chosen by the Northern firm in the case it cb oses e cort. Let $q^{s}$ denote the quantity produced after expiration of the patent $\mathrm{p}$, hen $\beta>0$, in general $q^{\tau} \neq q_{0}^{\tau}, q^{F D I} \neq q_{0}^{F D I}$ and $q^{s} \neq q_{0}^{s}$. This makes a global sysis (i.e., for any $\beta>0$ ) very difficult to conduct. To circumvent this difficulty we study the impact of a marginal technological improvement, i.e. in the neighborhood

\footnotetext{
${ }^{8}$ While countries may not actually choose patent length based on technology type there are many countries which actually enforce patent protection selectively and vary the length of protection based on differences in technology. Companies transferring technology to Indian firms (both through subsidiaries and unaffiliated firms) until the mid 1990's were only allowed to charge royalties for a period whose duration varied with the industry and the terms of the agreement. Many countries have loopholes in patent laws allowing non working patents to be appropriated. Thus while stated patent length may not vary by technology or industry, the enforcement of patent length clearly does vary.
} 
of $\beta=0$. Even a marginal technological improvement can have an ambiguous impact on the minimal FDI inducing patent length.

Lemma 1: A marginal decrease in the total cost by $\beta q$ will result in a decrease of the minimum FDI inducing patent length if and only if

$$
\frac{\pi_{0}^{F D I}}{q_{0}^{F D I}}-\frac{\pi_{0}^{\tau}}{q_{0}^{\tau}}>0
$$

where $q_{0}^{\tau}=q^{\tau}$ and $q_{0}^{F D I}=q^{F D I}$ when $\beta=0$.

Proof: We show in Appendix A that

$$
\frac{\partial L_{\tau}(0)}{\partial \beta}=\frac{e^{r L_{\tau}(0)}}{r} \frac{q_{0}^{F D I} q_{0}^{\tau}}{\left(\pi_{0}^{F D I}\right)^{2}}\left(\frac{\pi_{0}^{F D I}}{q_{0}^{F D I}} \tau^{\tau^{\tau}}\right)
$$

The lemma above raises a rather surprising possı lity: if $\left(\frac{\pi_{0}^{F \Gamma}}{q_{0}^{T}-}-\frac{\pi_{0}^{\tau}}{q_{0}^{\tau}}\right)<0$ the minimum FDI inducing patent length is reduces if $r$ or efficie-t+chnology does not necessarily imply that the South will have to ve 'onger length to attract FDI! If for example $q_{0}^{F D I}>q_{0}^{\tau}$, this surprisins po si sility varise when the average profit is decreasing with quantities.

If $\left(\frac{\pi_{0}^{F D I}}{q_{0}^{F D I}}-\frac{\pi_{0}^{\tau}}{q_{0}^{\tau}}\right)>0$ th $\frac{L_{\tau}\left(\iota_{\nu}\right.}{\partial \rho}>0$. technology one should offer $m$ e attravive incentive, i.e. a longer patent length. If this is true then e swer to the ntral question is nontrivial. Consider the three time intervals ${ }_{\tau},\left[L_{\tau}(0), L_{\tau}(\beta)\right)$ and $\left[L_{\tau}(\beta), \infty\right)$. During $\left[0, L_{\tau}(0)\right)$ the flow of welfare in $\mathrm{du}$ as to the technology improvement because the quantity supplied by the Northes fi $\mathrm{A}$ increases due to a decrease in the marginal cost. During $\left[L_{\tau}(\beta), \infty\right)$ the flow of weli, e increases due to technology improvement because the supply in the South increases since the marginal cost of production diminishes: $w^{F D I}>w_{0}^{F D I}$ where $w^{F D I}$ is the flow of welfare in the South during FDI with the new technology. However, during $\left[L_{\tau}(0), L_{\tau}(\beta)\right)$ the flow rate of welfare in the South prior the technology improvement is $w_{0}^{s}$ where as under the new technology it is $w^{F D I}$, with $w^{F D I}<w_{0}^{s}$ : a decrease in the flow of welfare. The overall impact of a technology improvement is thus a priori to be determined. 


\subsection{The impact of a technological innovation on South's welfare}

To be able to compute the overall impact of the technology improvement on the South's welfare we use specific functional forms for the demand function and the cost function. We argue that a technological improvement can have a negative effect of Sou 's welfare. This possibility can arise even in the very standard framework where the de $\mathrm{nd}$ ad the cost are respectively affine functions of the quantity consumed and pro 0 his is the case we consider from now on.

Suppose South's demand for the commodity produced by the $\mathrm{N}$ thern firm is given by:

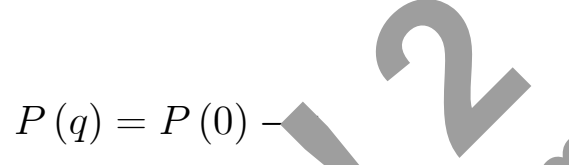

The marginal $\operatorname{cost}^{9}$ is constant and equal to $c>\sigma_{c} \mathrm{~d}$ the fixe 10 ost is $\phi \geq 0$.

Assume now that a technological innovain the plan and the marginal cost drops from $c$ to $c-\beta$, where $\beta \leq c$. The prof $\gamma_{c}$ imizing a antity chosen by the Northern firm during an export phase when it $\mathrm{S}$, sing a de unit tariff $\tau$ is given by:

where $z \equiv P(0)-$ s assumed positivio. The Northern firm's profits are

$$
\begin{aligned}
& \text { from va e in.er }{ }^{11} \\
& \qquad \pi^{F D I}=\left(q^{F D I}\right)^{2}-\phi \text { and } q^{F D I}=\frac{z+\beta}{2}
\end{aligned}
$$

\footnotetext{
${ }^{9}$ We assume identical costs in North and South. Our analysis can be extended to cases where the marginal cost $c_{S}$ in South and a marginal cost $c_{N}$ in North differ $\left(c_{N} \neq c_{S}\right)$.

${ }^{10}$ In the case of a linear cost function our analysis could be expressed as a comparative static exercise with respect to the marginal cost $c$. We keep our approach of using the parameter $\beta$ to be consistent with the analysis of the FDI inducing patent length conducted without assuming the linearity of the cost function.

${ }^{11}$ by setting $\tau=0$.
} 
The South's instantaneous social welfare under FDI is given by

$$
w^{F D I}=\int_{0}^{q^{F D I}} P(q) d q-P\left(q^{F D I}\right) q^{F D I}=\frac{\left(q^{F D I}\right)^{2}}{2}
$$

The maximum social welfare that can be generated in the South once patent protection expires is

$$
w^{s}=\int_{0}^{q^{s}} P(q) d q-(c-\beta) q^{s}-(\phi-\gamma)=\frac{\left(q^{s}\right)^{2}}{\gamma}
$$

where

$$
q^{s}=z+\beta
$$

Using Lemma 1, we show in appendix B that a aerease ir tre marginal cost will require a longer patent protection in South in $1 \mathrm{CF}$ FI fr $\mathrm{m}$ North.

Let $W^{F D I}(\beta)$ denote the present valy 9 Soun's woitcre,

$$
W^{F D I}(\beta)=\int^{L_{\tau}} w e^{D I} e^{-r t} \int_{L_{\tau}(\beta)}^{\infty} w^{s} e^{-r t} d t
$$

Deriving $W^{F D I}(\beta)$ wit respe to $\beta$ yielas

$$
\begin{aligned}
& \frac{d W^{F D I}}{d \beta}(\beta)=1^{L_{\tau}(\beta)} \frac{\partial w^{F D I}}{\partial q}-\frac{d q^{F}}{\tau} \frac{{ }^{F}}{\beta} e^{-r t} d t+ \\
& \int_{L_{\tau}(\beta)}^{c}\left(\frac{\partial w^{s}}{\partial q} \frac{d q^{s}}{d \beta}+\frac{\partial w^{s}}{\partial \beta}\right) e^{-r t} d t+\left(w^{F D I}-w^{s}\right) e^{-r L_{\tau}(\beta)} \frac{\partial L_{\tau}(\beta)}{\partial \beta}
\end{aligned}
$$

We have $\left.\frac{\omega^{s}}{3}\right|_{\beta=0}=q_{0}^{s}$, moreover, using the envelope theorem we have $\left.\frac{\partial w^{s}}{\partial q}\right|_{\beta=0}=0$ and thus

$$
\begin{aligned}
\frac{d W^{F D I}}{d \beta}(\beta=0)= & \int_{0}^{L_{\tau}(0)} \frac{\partial w^{F D I}}{\partial q} \frac{d q^{F D I}}{d \beta} e^{-r t} d t+ \\
& \int_{L_{\tau}(0)}^{\infty} q_{0}^{s} e^{-r t} d t+\left(w_{0}^{F D I}-w_{0}^{s}\right) e^{-r L_{\tau}(0)} \frac{\partial L_{\tau}(0)}{\partial \beta}
\end{aligned}
$$

Note that $w^{F D I}$ does not depend explicitly on $\beta$, however it depends on $q_{F D I}$ which is a function of $\beta$. 
The impact of such a cost reduction is fairly intuitive. The first two terms of the RHS are both positive and represent the increased welfare during the period of FDI because production will increase during FDI and, the increase in welfare "post FDI" after the expiration of the patent. The third term's sign is ambiguous and depends on the impact of the technology improvement. If the minimum FDI inducing patê length is shortened then the impact of the technology improvement is definitely ov (since $\left.w_{0}^{F D I}-w_{0}^{s}<0\right)$. If the patent protection is lengthened then the th sign is negative and the impact of the technology improvement on Soy s wels e is ambiguous.

For the linear demand and affine cost function as specified above ve have:

$$
\frac{d w^{F D I}}{d \beta}=q^{F D I} \frac{d q^{F D I}}{d \beta}>\gamma
$$

After substitution of $q^{F D I}$ and $q^{s}$ we have at $\beta=$

and $d w^{F} 20 \frac{z}{4} d q$

$$
w_{0}^{F D I}=\frac{z^{2}}{8} \text { and }=\frac{\gamma}{2}
$$

Lemma 2 : The impa ton, uth's velfare due to a change in the marginal cost is given by

where

$$
\frac{d W^{F D I}}{d \beta}(\beta=0)=\frac{z N\left(\frac{\phi}{z^{2}}, \frac{\tau}{z}\right)}{4 r\left(4 \frac{\phi}{z^{2}}-1\right)^{2}}
$$

$$
(\phi, \tau) \equiv\left(32 \frac{\tau}{z}+16\right)\left(\frac{\phi}{z^{2}}\right)^{2}+\left(4\left(\frac{\tau}{z}\right)^{2}-28 \frac{\tau}{z}-8\right) \frac{\phi}{z^{2}}+3 \frac{\tau}{z}+1
$$

Proof: see appendix C.

Without loss of generality we adopt the following normalization: $z=1$. The function $N(\phi, \tau)$ becomes

$$
N(\phi, \tau)=(32 \tau+16) \phi^{2}+\left(4 \tau^{2}-28 \tau-8\right) \phi+3 \tau+1 .
$$

The sign of $\frac{d W^{F D I}}{d \beta}$ will in general depend on $\phi$ and $\tau$. The signs of $\frac{d W^{F D I}}{d \beta}$ and of $N(\phi, \tau)$ are the same. 
We can unambiguously determine the sign of the expression $\frac{d W^{F D I}}{d \beta}(\beta=0)$ in $(17)$ for the case where $\phi=0$. From (17) we have $N(0, \tau)=1+3 \tau>0$ for $\tau \geq 0$ and thus $r \frac{d W^{F D I}}{d \beta}(\beta=0)>0$. When the fixed cost is zero, a decrease in the marginal cost will increase South's welfare. Using a continuity argument we can state that if the fixed cost $\phi$ is small enough ${ }^{12}$ a marginal decrease in the marginal cost increases South welfare.

Before analyzing the sign of $N(\phi, \tau)$ (and $\frac{d W^{F D I}}{d \beta}(\beta=0)$ by the same to to $\phi>0$ we first specify its domain of definition. We note that any tariff rate $\tau$, be larger than 1 (for production to take place ${ }^{13}$ ). Moreover, given a $t{ }^{\Upsilon} \tau \leq 1$ we must have $\phi \leq \phi_{\tau} \equiv \frac{(1-\tau)^{2}}{4}$ where $\phi_{\tau}$ represents the upper bound on the fixed $c_{-} \operatorname{ts}^{14}$ beyond which, when $\beta=0$, there would be losses from export $\left(\pi^{\tau}<0\right)$ he the tariff is $\tau$. We therefore limit the domain of the function $N(\phi, \tau)$ to $\left.\left[0, \phi_{\tau}\right],{ }^{r}, 1\right] \mathrm{w}$ cre $\phi_{\infty} \equiv \frac{(1-\tau)^{2}}{4}$.

Proposition 3: A lower marginal cost f $n$ a do ion car cult in a lower welfare in South.

Proof: See appendix D.

A lower marginal cost of prodı $n$, in redog welfare in South. More generally, it can be shown that there ex is $\tau \in(, 1)$ sucl rat for any $\tau \in(0, \bar{\tau})$ a lower marginal cost of production can result in $\quad r$ welf $f_{9}$ in South and for $\tau \in(\bar{\tau}, 1)$ a lower marginal cost of production $1 \mathrm{w}, \mathrm{s}$ result in a inger welfare in South. The approximate value of $\bar{\tau}$ is 0.1885 .

The in a chesults above is that a change in technology modifies the ratio oـ $r$ r ts under exports and with FDI, $\frac{\pi^{\tau}}{\pi^{F D I}}$. The sensitivity of the ratio $\frac{\pi^{\tau}}{\pi^{F D I}}$ to the cost var es with the level of the fixed cost. For a high level of fixed costs the profits are smaller in absolute value, therefore a change in marginal costs will relatively result in larger percentage changes of the profits if the fixed costs were smaller. In the benchmark case of a linear demand the relative change in $\pi^{\tau}$ exceeds the relative change in $\pi^{F D I}$

\footnotetext{
${ }^{12}$ More precisely, it can be shown that, for any $0<\phi<\frac{z^{2}}{8}$ we have $\frac{d W^{F D I}}{d \beta}(\beta=0)>0$.

${ }^{13}$ Recall that $z=1$. For $z \neq 1$ we should limit the domain of $\tau$ to $[0, z]$.

${ }^{14}$ Alternatively, $\tau$ can be interpreted as the prohibitive tariff that sets exports to zero when $\phi=\phi_{\tau}$.
} 
leading to an increase of the ratio $\frac{\pi^{\tau}}{\pi^{F D 1}}$. The increase of $\frac{\pi^{\tau}}{\pi^{F D 1}}$ requires the offering by South of a longer the patent length needed to induce FDI. The overall effect on welfare of a longer minimum FDI inducing patent length following a decrease in the marginal costs outweighs the positive effect of a lower marginal cost of production.

\section{Conclusion}

We find that a more effective technologies may not always be cessi te longer patent length in order to induce FDI. Since the Northern firm is more likely $p$ choose FDI when the cost reduction is more effective over large scale $\mathrm{p}$ do tion, if a firm has sharply increasing marginal costs, then the patent length o ${ }^{n}$ red by ne South could potentially be shorter and still promote FDI and result in a ver velfare south. In the case of a linear demand and affine cost function, wt ht that a d c ease of the marginal cost unambiguously requires offering a longer re ction.

In that case, there exists a thresh a vo f fixe a casts beyond which a decrease of the marginal cost results in a lowar Ifan Sor Technology changes adversely impact Southern welfare for two $r$ sons. To induce FDI, a Southern country has to increase the length of patent pro ${ }^{+}$tion orn d to t e Northern firm. While FDI is still the preferred to exports from So s welfare persective, the extra cost of acquiring FDI diminishes the South's Ifare 


\section{References}

[1] Brander, J.A., and Spencer, B.J.,(1987) "Foreign Direct Investment with unemployment and endogenous taxes and tariffs," Journal of International Economics 22, 257-279.

[2] Calton, D.C., and Perloff, J.M. (2005), Modern Industrial Organiz w Adison Wesley, 4th Edition.

[3] Chin, Judith C.; Grossman, Gene M., (1990) "Intellecua Property Rights and North-South Trade," in Jones, Ronald W.; Kruegr Inne O., eds.. The Political Economy of International Trade: Essays in honor of Rc se Ealdwin. Oxford and Cambridge, Mass.: Blackwell, 90-107.

[4] Deardorff, Alan V (1993), "Should Pate, t te tion be Extended to all Developing Countries," in Stern, Robert M., ed. If Mutilat 10 Mrading System: Analysis and Options for Change. Studies in t tet Aawonal Tre Policy. Ann Arbor: University of Michigan Press, 435-48.

[5] Diwan, Ishac, and Ro 'rik, Jani, Tly1) "Patents, Appropriate Technology, and North-South T ade" Journal os Nuernational Economics, 30(1-2), 27-47.

[6] Ferrant; o, M. hat J. (1993), "The Effect of Intellectual Property Rights on Internat: It d and Investment," Weltwirtschaftliches Archiv 129, 300 - 331.

[7] Fuma 1 li, Chiara, (2003), "On the welfare effects of competition for foreign direct investments," European Economic Review 47, 963-983

[8] Glass, Amy Jocelyn and Saggi, Kamal (2001), "Innovation and Wage Effects of International Outsourcing," European Economic Review 45, 67-86.

[9] Glass, Amy Jocelyn and Saggi, Kamal (2002a), "Licensing versus Direct Investment: Implications for Economic Growth," Journal of International Economics 56, 131-53. 
[10] Glass, Amy Jocelyn and Saggi, Kamal (2002b), "Intellectual Property Rights and Foreign Direct Investment," Journal of International Economics 56, 387-410.

[11] Haufler Andreas, and Wooton, Ian, (1999) "Country Size and tax competition for foreign direct investment," Journal of Public Economics 71,121-139.

[12] Lee Jeong-Yeon and Mansfield, Edwin (1996), "Intellectual Property P oct n and U.S. Foreign Direct Investment", The Review of Economics an ${ }_{+}$ics $78(2)$, 181-186.

[13] Mattoo, Aaditya, Marcelo Olarreaga and Kamal S ri (2004), "Mode of Foreign Entry, technology transfer and FDI policy," Journat of D Jelopment Economics 75, 95-111.

[14] Taylor, M. Scott, (1993) "TRIPS, Trade n Te hnolog STansfer," Canadian Journal of Economics 26(3), 625-37.

[15] Varian, Hal R., (2002), Interm Jitc Micropromics, Norton, 6th Edition.

[16] Vishwasrao, Sharmila 1994, "ritellectarl Property Rights and the Mode of Technology Transfer." Jourr. Deve nent Economics 44(2), 381-402.

[17] Wang, Her- à B.Z. Yang 2001), "Fixed and sunk costs revisited", Journal of Econom. Educ tion, 32 (2), 178-85.

[18] Zig Aresimir (1998), "Intellectual Property Rights Violations and spillovers in North-nouth Trade," European Economic Review 42, 1779-1799. 


\section{Appendix A: Proof of Lemma 1}

The minimum FDI inducing patent length is such that

$$
e^{-r L_{\tau}(\beta)}=1-\frac{\pi^{\tau}}{\pi^{F D I}}
$$

Taking the derivative with respect to $\beta$ gives

$$
-r \frac{\partial L_{\tau}(\beta)}{\partial \beta} e^{-r L_{\tau}(\beta)}=-\frac{\left(\frac{\partial \pi^{\tau}}{\partial q} \frac{d q^{\tau}}{d \beta}+\frac{\partial \pi^{\tau}}{\partial \beta}\right) \pi^{F D I}-\left(\frac{\partial \pi^{F D I}}{\partial q} \frac{d q^{F D I}}{d \beta}-\frac{\partial \pi}{\tau \beta}\right)}{\left(\pi^{F D I}\right)^{2}}
$$

or

$$
-r \frac{\partial L_{\tau}(\beta)}{\partial \beta} e^{-r L_{\tau}(\beta)}=-\frac{\left(\frac{\partial \pi^{\tau}}{\partial q} \frac{d q^{\tau}}{d \beta}+q^{\tau}\right) \pi^{F D I}-\left(\frac{\partial \pi^{F D I}}{d q^{F D I}}+q^{F D I}\right) \pi^{\tau}}{\left(\pi^{F}-\sigma^{T}\right)^{2}}
$$

At $\beta=0$, using the envelope theorem : $\frac{\partial \pi^{\tau}}{\partial q}=\frac{\partial \pi^{F D}}{\partial q} \quad 0$ when $\beta=\mathbf{a}$ and thus

which gives

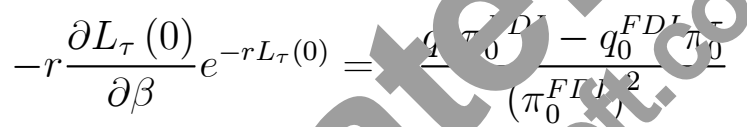

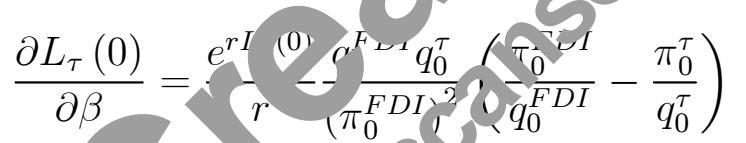

Appendix B: $\frac{\partial L_{\tau}(0)}{\partial \beta}>$

We use (8)

$$
\frac{\partial L_{\tau}(0)}{\partial \beta}=\frac{\rho^{-}(0)}{r} \frac{q_{0}^{F D I} q_{0}^{\tau}}{\left(\pi_{0}^{F D I}\right)^{2}}\left(\frac{\pi_{0}^{F D I}}{q_{0}^{F D I}}-\frac{\pi_{0}^{\tau}}{q_{0}^{\tau}}\right)
$$

and substitnt $\gamma_{\tau}, O{ }_{D I}, \pi^{\tau}, \pi^{F D I}$ from (9), (11) and (10) when $\beta=0$ and $\gamma=0$. This gives

$$
\frac{\partial L_{\tau}(0)}{\partial \beta}=\frac{e^{r L_{\tau}(0)}}{r} \frac{q_{0}^{F D I} q_{0}^{\tau}}{\left(\pi_{0}^{F D I}\right)^{2}}\left(\frac{\left(q_{0}^{F D I}\right)^{2}-\phi}{q_{0}^{F D I}}-\frac{\left(q_{0}^{\tau}\right)^{2}-\phi}{q_{0}^{\tau}}\right)
$$

Let

$$
h(\tau) \equiv \frac{\pi_{0}^{\tau}}{q_{0}^{\tau}}=\frac{\left(q_{0}^{\tau}\right)^{2}-\phi}{q_{0}^{\tau}}
$$

we have

$$
\frac{\pi_{0}^{F D I}}{q_{0}^{F D I}}-\frac{\pi_{0}^{\tau}}{q_{0}^{\tau}}=h(0)-h(\tau)
$$


It is straightforward to show that

$$
h^{\prime}(\tau)=\frac{d\left(q_{0}^{\tau}-\frac{\phi}{q_{0}^{\tau}}\right)}{d \tau}=\left(1+\frac{\phi}{\left(q_{0}^{\tau}\right)^{2}}\right) \frac{d q_{0}^{\tau}}{d \tau}<0
$$

and thus $h(0)-h(\tau)<0$ for all $\tau>0$, which gives

$$
\frac{\partial L_{\tau}(0)}{\partial \beta}=\frac{e^{r L_{\tau}(0)}}{r} \frac{q_{0}^{F D I} q_{0}^{\tau}}{\left(\pi_{0}^{F D I}\right)^{2}}(h(0)-h(\tau))>0
$$

\section{Appendix C: Proof of Lemma 4}

Substituting $w^{F D I}, w^{s}, \frac{d w^{F D I}}{d \beta}$ and $\frac{\partial L_{\tau}(0)}{\partial \beta}$ into (16) y

$$
\begin{aligned}
& \frac{d W^{F D I}}{d \beta}(\beta=0)=\frac{z}{4} \frac{\left(1-e^{-r L_{\tau}(0)}\right)}{r}+\frac{e^{-r L_{\tau}}}{r}+
\end{aligned}
$$

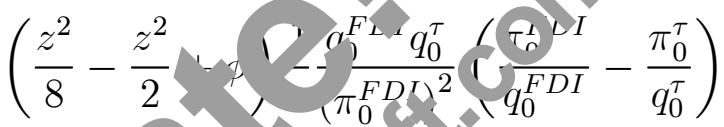

where

$$
q_{0}^{\tau}=\frac{z-\tau+\beta}{2}, q_{0}^{F D I}=\frac{z+\beta}{2}
$$

When $\beta=0$, the minimun FDI i ducing patent length is given by

$$
e^{-r L_{\tau}(0)}=\frac{\pi_{0}^{\tau}}{\pi_{0}^{F D I}}=\frac{\tau(2 z-\tau)}{4\left(\left(\frac{z}{2}\right)^{2}-\phi\right)}
$$

Substitutı $e^{-r} \cdot(0)$ into $\frac{d W^{F D I}}{d \beta}(\beta=0)$ gives after factorization

$$
\begin{aligned}
r \frac{d W^{F_{2}}}{d \beta}(\beta=0)= & \frac{z}{4}\left(1-\frac{\tau(2 z-\tau)}{4\left(\left(\frac{z}{2}\right)^{2}-\phi\right)}\right)+\frac{z}{4} \frac{\tau(2 z-\tau)}{\left(\left(\frac{z}{2}\right)^{2}-\phi\right)}+ \\
& \left(\frac{z^{2}}{8}-\frac{z^{2}}{2}+\phi\right) \frac{z(z-\tau)}{4\left(\left(\frac{z}{2}\right)^{2}-\phi\right)^{2}}\left(\frac{\left(\frac{z}{2}\right)^{2}-\phi}{\frac{z}{2}}-\frac{\left(\frac{z-\tau}{2}\right)^{2}-\phi}{\frac{z-\tau}{2}}\right)
\end{aligned}
$$

which after simplification yields

$$
r \frac{d W^{F D I}}{d \beta}(\beta=0)=\frac{z^{5}-8 z^{3} \phi+16 z \phi^{2}+3 z^{4} \tau-28 z^{2} \tau \phi+4 z \tau^{2} \phi+32 \tau \phi^{2}}{4\left(-z^{2}+4 \phi\right)^{2}}
$$


The numerator can be written $z^{5} N\left(\frac{\phi}{z^{2}}, \frac{\tau}{z}\right)$ where

$$
N(\phi, \tau)=\left(32 \frac{\tau}{z}+16\right)\left(\frac{\phi}{z^{2}}\right)^{2}+\left(4\left(\frac{\tau}{z}\right)^{2}-8-28 \frac{\tau}{z}\right) \frac{\phi}{z^{2}}+3 \frac{\tau}{z}+1 \boldsymbol{\square}
$$

\section{Appendix D: Proof of Proposition 3}

We provide an example where a lower marginal cost of production cas es it in a lower welfare in South. Let $\tau=\frac{1}{8}$. We have $\phi_{\tau}=\frac{49}{256} \approx 0.19141$ and

$$
N\left(\phi, \frac{1}{8}\right)=20\left(\phi-\frac{11}{64}\right)\left(\phi-\frac{2}{3}\right) \text {. }
$$

Therefore, for $\tau=\frac{1}{8}$ and all $\phi \in\left(\frac{11}{64}, \frac{49}{256}\right)$ we hav $\mathcal{V}\left(\phi, \frac{1}{8}<0\right.$ which is equivalent to $\frac{d W^{F D I}}{d \beta}(\beta=0)<0$ : a lower marginal cost of prod + tion mplies fower welfare in South!

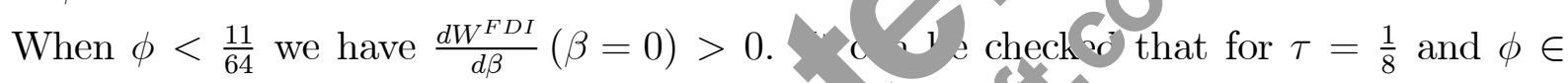
$\left(\frac{11}{64}, \frac{49}{256}\right)$, FDI is preferred to exports by ov

\footnotetext{
${ }^{15}$ Inequality (4), where $L=L_{\tau}(0)$, holds.
} 